\title{
The Physical and Behavioural Consequences of Facebook Use among University Students
}

\author{
Kwaku Oppong Asante \\ Discipline of Psychology, School of Applied Human Sciences, University of KwaZulu-Natal, Durban 4041, South Africa \\ Department of Psychology, Regent University College of Science \& Technology, Accra, Ghana \\ Email: kwappong@gmail.com \\ Jacob Nyarko \\ Center for Communication and Media Studies, University of KwaZulu-Natal, Durban, South Africa \\ School of Applied Arts, Takoradi Polytechnic, Post Office Box 256, Takoradi - Western Region, Ghana
}

\section{Doi:10.5901/mjss.2014.v5n27p774}

\section{Abstract}

Facebook is considered as one of the popular social network among young adults including university students globally. However, little studies have examined the adverse health behaviours associated with extensive Facebook use. Using a randomly selected 648 students from two universities in Ghana and a self-administered questionnaire, this study examined relationships between adverse health effects and unhealthy behaviours among university students using Facebook. Age of students ranged from 18-34, with an average age of 23.27(SD = 3.21). Over $57.5 \%$ of the participants spend over one hour on Facebook daily. Students who spend more than an hour on Facebook daily were less likely to answer telephone calls $(O R=$ 5.24; $95 \% \mathrm{Cl}=2.49-11.03)$, postponing of meals $(\mathrm{OR}=0.32 ; 95 \% \mathrm{Cl}=0.20-0.50)$, feel isolated from family $(\mathrm{OR}=0.42 ; 95 \% \mathrm{Cl}$ $=0.28-0.61)$, society $(O R=0.16 ; 95 \% \mathrm{Cl}=0.08-0.34)$ but more likely to hold urine $(\mathrm{OR}=2.67 ; 95 \% \mathrm{Cl}=1.82-3.90)$, faeces $(O R=1.69 ; 95 \% \mathrm{Cl}=1.14-2.51)$ and skip breakfast $(\mathrm{OR}=1.53 ; 95 \% \mathrm{Cl}=1.02-2.28)$. Excessive daily Facebook use was also associated with wrist pains $(O R=1.66 ; 95 \% \mathrm{Cl}=1.08-2.54)$. These findings showed that excessive Facebook use had both physical and musculoskeletal health effects on students. Health promotion and interventions are necessary in institutions of higher educations to guide young people towards a healthy use of social media like Facebook. Such interventions should focus on self-control of Facebook use, and periodic screening for musculoskeletal disorders.

Keywords: Facebook, social media, health effects, university students,

\section{Introduction}

Facebook which was created in 2004, and opened its site to the general public in 2006 (Sheldon, 2008) is considered as the leading social network site for young adults who are at the university (Golder, Wilkinson, \& Huberman, 2007). Facebook is still exponentially growing in popularity, as at the end of 2012, Facebook was estimated to have approximately 1.23 billion users with more than 500 million of those users log on to the site every day (Kiss, 2014). As a social network site, Facebook essentially allows individuals to share personal information, photographs and join a group of friends with one another (Buckman, 2005). As a social network developed with the intention to support social connection and network of friends, Facebook allows its users not only to communicate with one another but also to share photos, reveal personal information, comment on some topics, or play. Based on the multiplicity of its applications, Facebook can be described as playing different roles, ranging from a method of communication, a platform for entertainment, or a tool for self-promotion to its role in business (Błachnio, Przepiórka, \& Rudnicka, 2013).

Several studies have indicated that Facebook has fulfilled the purpose for which it was created. Some of the motives identified for Facebook use among young adults, especially students include maintaining friendship (Ellison, Vitak, Gray, \& Lampe, 2014; Hew, 2011), meet new people (Sheldon, 2008), to make oneself popular (Pempek, Yermolayeva, \& Calvert, 2009; Lee, 2014) and for educational purposes (Bosch, 2009). These benefits have thus made the platform both as a basic tool and a mirror for social interaction, personality identity and network building amongst students (Lewis \& West, 2009). In addition to the above mentioned motives for Facebook, researchers have started turning their attention to the effects of extensive Facebook use especially among students. Facebook addiction is the new term invented by researchers, as its addictive nature affects various health related behaviours (Kuss \& Griffiths, 2011). In 
fact, excessive Facebook use has been shown to be associated with poor academic performance, in the form of lower GPAs (Kirshner \& Karspinsk, 2010), low self-esteem (Denti, et al., 2012; Tobin, Vanman, Verreynne, \& Saeri, 2014), sleep disorders and depression (Kim et al., 2006; Rosen et al., 2013) and emotional wellbeing (Kalpiduo, Costin \& Morris, 2011). Recently, a study of medical students in Malaysia found that the number of hours spent on Facebook was associated with holding of urine and defecation while online (Al-Dubai et al., 2014). The same study reported that revealed that postponing and skipping of meals, as well as feeling isolated from family were associated with hours spent on Facebook (Al-Dubai et al., 2014). Other studies such as the one conducted by Campisi et al. (2012) revealed an association between Facebook use, psychological stress, and health. Campisi and colleagues indicated that students who had larger social network size reported significantly higher incidence of upper respiratory infections (URI), such that, the larger the social network of a student, the greater the incidence rate of URI. The same study reported that majority of their participants (87.5\%) reported some degree of Facebook-induced stress (Campisi et al., 2012).

Internet use in Ghana has been on the rise at an accelerated pace, with a penetration rate of $14.1 \%$ of the over 167 million internet users in Africa (World Internet Stats, 2012). Active users of social network site (Facebook) in Ghana is approximately 1.5milloin, making Ghana the 8th country in sub-Saharan Africa with a large number of Facebook users (World Internet Stats, 2012). Out of these 1.5 million users, approximately 69\% of them are male (Ghana Online, 2014). Research conducted in Ghana has shown that students rarely used Facebook for academic purposes. In a study conducted by Aforo (2014) to examine the impact of social media on academic reading among university students, indicated that although over $94 \%$ of the students indicated Facebook as their preferred social media, only $23.3 \%$ stated that they access educational materials from their interaction with social media. This, thus suggest that the entertainment options of social media platform looks more appealing (Aforo, 2014).

From the above literature review and to the best of the knowledge of the researchers, no study have examined the prevalence of unhealthy behaviours as well as physical and musculoskeletal health effects of extensive Facebook use among students within the Ghanaian context. The aim of this study was to examine relationships between adverse health effects and unhealthy behaviours among university students using Facebook. The main research questions to be examined are: 1) what is the prevalence of unhealthy behaviours, physical and musculoskeletal health effects of prolong Facebook use 2) what are the health problems associated with prolong Facebook use among university students in the western region of Ghana. The findings of this study could inform interventions that could target university students who could be at risk for physical and musculoskeletal disorders associated with Facebook use.

\section{Method}

\subsection{Participants and procedure}

Samples of 648 university students were randomly selected from two public tertiary institutions in the Western Region of Ghana. The sample consisted of 384 males and 264 females. In each university, lecture rooms were randomly selected from a list of available lecture rooms in the university, and on the days of data collection, any student in the selected lecture rooms participated in the study. Students filled a written consent form, and data collection took place in the lecture rooms after a teaching session had ended in the absence of the researchers. To ensure anonymity, no form(s) of identifiers were on the questionnaire and the participants were informed that participation was voluntary and they could withdraw from the study at any stage if they so desire. Ethical approval was obtained from the Takoradi Polytechnic Research Committee, after each of the participating universities had given permission for their students to participate in the study. Sample size was determined a priori using GPower software version 3.1 (Faul, Erdfelder, Lang, \& Buchner, 2007). With a power value of 0.80 , a significant level of 0.10 , and a minimum effect size of 0.10 , the minimum sample size was calculated to be 448 .

\subsection{Measures}

The questions used to access the variables in this study were structured and formulated based on the previous studies conducted on Facebook use among university students in developed countries. We assessed socio-demographic characteristics (gender, age, marital status, year of study, family background), Facebook use and attitudes, health related behaviours during Facebook use, perceived isolation from family and society during Facebook use and adverse physical health related to Facebook use. 


\subsubsection{Facebook Measures}

Five measures on Facebook use adapted from the Facebook Intensity Scale (Ellison et al., 2007). These questions include duration of daily Facebook use (Less than 10 minutes $=1,10-30$ minutes $=2,31-60$ minutes $=3,1-2=4$, '2-3 hours $=5$, and more than 3 hours $=6 ")$, Number of Facebook friends, Number of Facebook albums, duration of having Facebook profile ( 6 months or less $=1,1$ year $=2,1.5$ years $=3,2$ years $=4,2.5$ years $=5$, and 3 years and over $=6$ ), and preferred Facebook function (Facebook wall $=1$ and Facebook message $=2$ ).

\subsubsection{Health-related behaviours}

Five questions were used to assess student's health-related behaviours during the use of Facebook. These questions include holding defecation, holding urine, skipping of breakfast, postponing of meals, and using Facebook until midnight. The response to these questions was in the format of "Not at all" sometimes and always. These responses were subsequently recoded into a categorical variable such that "Not at all $=0$, and Sometimes and Always $=1$

\subsubsection{Perceive isolation from family and society}

Three items namely (1) feel isolated from the family, (2) feel isolated from the society, (3) refuse to answer calls were used to measure perceived isolation. These questions were in the format of yes/no.

\subsubsection{Adverse physical health effects}

Five questions were used to assess possible adverse physical health effect student's night have experience during the past one month of using Facebook. Questions asked included back pain, shoulder pains, wrist pain, eye irritation and headache. The response to these questions was in the format of "Not at all" sometimes and always. These responses were subsequently recoded into a categorical variable such that "Not at all $=0$, and Sometimes and Always = 1 .

\subsection{Data Analysis}

The questionnaires were checked for completeness and data was entered into Microsoft Excel 2007 spreadsheet. This was subsequently imported into SPSS software version 21, which was to conduct data analysis. Logistic regression was used to examine any association between Facebook use and the various explanatory variables. The results from the logistic regression analyses are presented as odds ratios (OR) with 95\% confidence intervals (Cls). Statistical significance was defined as a two-tailed $p$ value $<0.05$ in all analyses.

\section{Results}

\subsection{Demographic characteristics of participants}

The 648 participants included $59.3 \%$ and $40.7 \%$ of male and female respectively. Age of students ranged from 18-34, with an average age of $23.27(S D=3.21)$. The majority of the participants were in their second year $(55.7 \%)$, single (71.0\%) and quite well-off in terms of socio-economic background (74.0\%). Over $57.5 \%$ of the participants spend over one hour on Facebook daily (range: 1-5 hrs.). Approximately $61 \%$ have had Facebook account for over three years, and over half (51.4\%) preferred the Facebook Wall as a function on Facebook, and majority (84\%) had over 100 Facebook friends (Table 1) 
Table 1: Socio-demographic information of the participants $(n=648)$

\begin{tabular}{|c|c|c|}
\hline Characteristics & Number & $\%$ \\
\hline \multicolumn{3}{|l|}{ Gender } \\
\hline Male & 384 & 59.3 \\
\hline Female & 264 & 40.7 \\
\hline \multicolumn{3}{|l|}{ Marital Status } \\
\hline Single & 456 & 71.0 \\
\hline Relationship & 138 & 21.5 \\
\hline Married & 48 & 7.5 \\
\hline \multicolumn{3}{|l|}{ Year of study } \\
\hline First year & 78 & 12.3 \\
\hline Second year & 354 & 55.7 \\
\hline Third year & 36 & 5.7 \\
\hline Fourth year & 168 & 26.4 \\
\hline \multicolumn{3}{|l|}{ Family Background } \\
\hline Wealthy (within the top 25\%) & 90 & 15.6 \\
\hline Quite well off (within the 50\%- 75\% range) & 426 & 74.0 \\
\hline Not well off (within the $25 \%$-50\% range) & 42 & 7.3 \\
\hline Quite poor (within the lowest 25\%) & 18 & 3.1 \\
\hline \multicolumn{3}{|l|}{ Duration of Having FB page } \\
\hline$\leq 1$ year & 126 & 19.4 \\
\hline $1-2$ years & 126 & 19.4 \\
\hline$\geq 3$ years & 396 & 61.2 \\
\hline \multicolumn{3}{|l|}{ Preferred Facebook function } \\
\hline Facebook Wall & 330 & 51.4 \\
\hline Facebook Message & 312 & 48.6 \\
\hline \multicolumn{3}{|l|}{ Number of hours spent on Facebook daily } \\
\hline$\leq 1 \mathrm{hr}$. & 270 & 42.5 \\
\hline $1-2$ hrs. & 228 & 35.8 \\
\hline 2-3hrs. & 96 & 15.1 \\
\hline$\geq 3 \mathrm{hrs}$. & 32 & 6.6 \\
\hline \multicolumn{3}{|l|}{ Number of Facebook Friends } \\
\hline$\leq 100$ & 102 & 16.0 \\
\hline $100-300$ & 264 & 41.5 \\
\hline$\geq 301$ & 270 & 42.5 \\
\hline \multicolumn{3}{|l|}{ Medium to access Facebook } \\
\hline Mobile phone & 462 & 71.3 \\
\hline Laptop computers & 132 & 20.3 \\
\hline Other (desktop/tablets) & 54 & 8.4 \\
\hline
\end{tabular}

\subsection{Prevalence of behaviours associated with Facebook use}

Table 2 shows the prevalence of physical adverse health effects, unhealthy health behaviours and perceived social isolation behaviours associated with Facebook usage among the participants in the study. With regards to un-healthy health behviours, about $75.9 \%$ of the participants use Facebook until midnight. While majority $(71.3 \%)$ of the participants reported to postponing taking their mails, only $41.7 \%$ reported to skip breakfast because of Facebook use. Holding urine and defecation were reported by $57.4 \%$ and $52.8 \%$ of the students respectively reported to engaged in such behaviours due to the use of Facebook. Only a third of the participants reported feeling isolated. With regards to adverse physical effect, eye irritation and headaches were reported by $61.1 \%$ and $63.0 \%$ of the sample students. Musculoskeletal health effects such as back pains (63.0\%), shoulder pains (75.0\%) and wrist pains (61.1\%) were reported by the students as well. 
Table 2: Health Behaviours of the sample during Facebook use in the past one month

\begin{tabular}{lll}
\hline Behaviours & N & $\%$ \\
\hline Health-related behaviours & & \\
Holding defecation & 342 & 52.8 \\
Holding urine & 372 & 57.4 \\
Skipping of breakfast & 270 & 41.7 \\
Postponing of meals & 462 & 71.3 \\
Using Facebook until midnight & 492 & 75.9 \\
Perceive isolation from family and society & & \\
Feel isolated from the family & 312 & 48.1 \\
Feel isolated from the society & 216 & 33.3 \\
Refusing to answer calls & 186 & 28.7 \\
Adverse physical health effects & & \\
Back pains & 408 & 63.0 \\
Shoulder pains & 486 & 75.0 \\
Wrist pains & 396 & 61.1 \\
Eye irritation & 396 & 61.1 \\
Headaches & 408 & 63.0 \\
\hline
\end{tabular}

Table 3: Odds ratios (OR) and 95\% confidence intervals $(\mathrm{Cl})$ for undesirable health behaviours associated long hours of Facebook use

\begin{tabular}{|c|c|c|}
\hline Predictors & UOR $(95 \% \mathrm{Cl})$ & AOR $(95 \% \mathrm{Cl})^{\mathrm{a}}$ \\
\hline \multicolumn{3}{|l|}{ Health-related behaviours } \\
\hline Holding defecation & $1.69(1.14-2.51)^{\star *}$ & $1.14(1.03-1.93)^{\star *}$ \\
\hline Holding urine & $2.67(1.82-3.90)^{* * *}$ & $2.18(1.58-3.04)^{* *}$ \\
\hline Skipping of meal & $1.53(1.02-2.28)^{*}$ & $1.94(1.40-2.68)^{* *}$ \\
\hline Postponing of meals & $0.32(0.20-0.50)^{* * *}$ & $0.54(0.38-0.78)^{* \star *}$ \\
\hline Using Facebook until midnight & $1.03(0.66-1.59)$ & ------ \\
\hline \multicolumn{3}{|c|}{ Perceive isolation from family and society } \\
\hline Feel isolated from the family & $0.42(0.28-0.61)^{\star * \star}$ & $0.59(0.43-0.82)^{\star \star \star}$ \\
\hline Feel isolated from the society & $0.16(0.08-0.34)^{\star \star \star *}$ & $0.21(0.18-0.48)^{\star \star *}$ \\
\hline Refusing to answer calls & $5.24(2.49-11.03)^{* * *}$ & $4.22(2.18-9.41)^{* * *}$ \\
\hline \multicolumn{3}{|l|}{ Adverse physical health effects } \\
\hline Back pains & $0.94(0.60-1.48)$ & ------- \\
\hline Shoulder pains & $1.22(0.79-1.89)$ & -------- \\
\hline Wrist pains & $1.66(1.08-2.54)^{*}$ & $2.74(1.30-5.33) *$ \\
\hline Eye irritation & $1.21(0.78-1.87)$ & ------ \\
\hline Headaches & $0.94(0.61-1.45)$ & -------- \\
\hline
\end{tabular}

\subsection{Association between Facebook use and other unhealthy health behaviours}

In bivariate analysis, unhealthy behaviours such as holding defecation, urine, skipping breakfast, musculoskeletal health effects such as wrist pains and refusing to answer phone calls were found to be associated with long hours of Facebook use. In the same analysis, students who use Facebook for long hours were less likely to postpone meals, and feel isolated from both family and society. In the multivariate logistic analysis, after adjusting for socio-demographic characteristics, two adverse health behaviours (holding of defecation and urine), wrist pains, skipping breakfast and refusing to ask telephone calls were found to be associated with long hours of Facebook use. Students using Facebook over an hour a day were less likely to postpone meals and feel isolated from family and society (Table 3 ).

\section{Discussion}

Facebook which is considered as the leading social network site for young adults, at the university, have adverse effects on health and behaviour of its users. Our goal was to to examine the prevalence of unhealthy behaviours, physical and 
musculoskeletal health effects of prolonged Facebook use and to find out the health problems that are associated with it use among university students in the western region of Ghana. Over $57.5 \%$ of the participants spend over one hour on Facebook daily. Students who spend more than an hour on Facebook daily were less likely to answer telephone calls, and more likely to hold urine, faeces and skip breakfast but not postpone their meals Excessive daily Facebook use was also associated with writs pains but not back and shoulder pains.

This study found that daily use of Facebook was high as over $57 \%$ of the participants spend between one to five hours on Facebook. This confirm with other studies (Al-Dubai et al., 2013; Peltzer, Pengpid, \& Apidechkul, 2014), yet other studies found a much lower rates of heavy Facebook use among university students in the United States (Kalpidou, Costin, \& Morris, 2011; Raacke \& Bonds-Raacke, 2008). In a study carried out in the United States among college students who had accounts on various SNSs, including Facebook, Raacke and Bonds-Raacke (2008), found that an average of 3 hours per day was spent communicating or posting messages on these SNSs. The arbitrary cut-off points and the lack of information on the purpose of what students were doing during the long hours of Facebook use should be addressed in future studies. It is however known that students in Ghana rarely use Facebook for academic purposes (Aforo, 2014). In the United States for instance one out of ten students uses Facebook for academic work (Raacke \& Bonds-Raacke, 2008).

Almost 6 out of 10 students reported having experienced some form of musculoskeletal health effects such as back pains (63.0\%), shoulder pains (75.0\%) and wrist pains (61.1\%). The prevalence rate of $61 \%$ reported for wrist pains was lower than $66 \%$ reported by medical students in Malaysia (Al-Dubai et al., 2014) but higher than the $40 \%$ reported among students in China (Smith et al., 2005). The high prevalence of musculoskeletal must be a concern for health educators as this could have a delirious effect on their health and that providing early support and preventive measures are necessary for a better physical health of students. Some of the differences in the high prevalence of musculoskeletal pains reported in this study compared to other studies are difficult to explain but this could be attributed to the cultural patterns in which students from different countries report musculoskeletal problems, with students downplaying the prevalence in some countries and in other countries students may more likely complain (Allison et al., 2002). What we cannot determine is whether these musculoskeletal effects are lifetime or episodic, as reporting musculoskeletal pains do not necessarily mean that the pains are continuous. It is however known that a study conducted in Malaysia indicated that students who have musculoskeletal pains have had continuous pain while others may have had only consecutive pain episodes (Al-Dubai et al., 2014).

With regards to the association between Facebook use and musculoskeletal problems, we observed that an increasing Facebook use was associated with wrist pains but not back and shoulder pains during the past one month. This findings was consistent with a study conducted by Al-Dubai et al., 2014 but contradicts those found in other countries (Hakala, Rimpelä, Saarni, \& Salminen, 2006; Juul-Kristensen, Søgaard, Støyer, \& Jensen, 2004). This significant association could be attributed to the medium of accessing Facebook, as over $71 \%$ of the participants in this study indicated to using their mobile phones, which required excessive use of the fingers.

Consistent with the results of a study conducted in Malaysia (Al-Dubai et al., 2014), this study found in both bivariate and multivariate analysis that skipping breakfast, and not postponing of meals were associated with Facebook use. This finding also corroborates a study which indicated that students who use internet heavily were more likely to skip breakfast (Peltzer \& Pengpid, 2014). A possible explanation for this relationship could be due to the fact that students who use Facebook excessively stay online late into the night and may get up too late and therefore likely to skip breakfast before classes. Again in Ghana, it is estimated that about $52 \%$ of the populations are below the poverty line, and therefore less likely to be concerned about breakfast, as planning what and when to eat could be considered as luxury (Doku, Koivusilta, Raisamo, \& Rimpelä, 2013). It is however, important for health interventions to address the high rate of skipping breakfast reported in this study as regular intake of breakfast increases the possibility of a balanced diet and improves overall nutritional status and nutritional density, particularly during the early phases of life( Nicklas, O'Niel, \& Meyers, 2004).

Further, the study found that feeling isolated from family and the society was inversely associated with long hours of Facebook. This finding does contradicts the premise of the gratification theory which suggested that the use of the internet and social network may influence individual interaction and participation in several real life situations (Raacke \& Bonds-Raacke, 2008). Thus, the use of Facebook among the students in this study does not serve as a means for social escapism and an avenue to pass time. This study also found significant associations between Facebook surfing hours and unhealthy behavioural actions like holding urine and defecation. This finding add to the existing literature that have indicated various behavioural problems such as depression, sleep disorders, excessive fatigue, inattention and emotional wellbeing to be associated with excessive use of social networks including Facebook (Kirshner \& Karspinsk, 2010; Denti, et al., 2012; Tobin et al., 2014; Kim et al., 2006; Rosen et al., 2013; Kalpiduo et al., 2011). What this implies is that in 
addition to the above mentioned behavioural problems, unhealthy behaviours such as holding of both urine and faeces as shown in this study are associated with Facebook use. We could attribute the high prevalence of such behaviours to the multiplicity of Facebook functions, and the attractiveness of attention of the platform (Błachnio et al., 2013).

\section{Limitations of the Study}

The findings of this study must be interpreted cautiously in the light of some important limitations. This study was conducted among full-time undergraduate students at two large public universities in the Western region of Ghana. Consequently, our findings may not reflect university students in other geographic regions in Ghana. Furthermore, the study relied on self-report use of Facebook use, which could have been subject to social desirability bias or memory bias. Thus, further studies may benefit from more objective assessments of Facebook use. Furthermore, these findings are likely specific to undergraduate students, and may not necessarily reflect the relationship between Facebook use and adverse health behaviours among other populations of the same age who are not in universities or of other age groups. Finally, future studies are needed to determine the direction of the relationship between Facebook use and adverse health behaviours. It would be interesting to determine whether adverse health behaviours lead to extensive daily Facebook use or vice versa. Facebook addiction was not evaluated in this study; only extensive Facebook use was studied.

\section{Conclusion}

In sum, Facebook which is considered as the leading social network site for young adults including students, have also been shown to have effects on various spheres of human behaviour. Our main objective was to examine relationships between adverse health effects and unhealthy behaviours among university students using Facebook, in order to help inform interventions that could target university students who could be at risk for physical and musculoskeletal disorders associated with Facebook use. The results showed that excessive Facebook use had both physical and musculoskeletal health effects on students. Health promotion and interventions are necessary in institutions of higher educations to guide young people towards a healthy use of social media like Facebook. Such interventions should focus on self-control of Facebook, and periodic screening for both eye and musculoskeletal disorders. Although the study on the psychosocial effects of Facebook use in Ghana is still in infancy, the fact that young people are exposed to several social networking sites from early adolescence makes it imperative for researchers to understand the effect they have on their physical and psychological well-being. All in all, our study provides evidence of a relationship between Facebook and adverse health behaviours in some contexts highlighting the need to examine how some types of online interactions can have negative effect on behavioural and physical health outcomes.

\section{References}

Aforo, A. A. (2014). Impact of Social Media on Academic Reading: A Study at Kwame Nkrumah University of Science and Technology, Kumasi, Ghana. Asian Journal of Humanities and Social Studies, 2(1).

Al-Dubai, S. A. R., Ganasegeran, K., Al-Shagga, M. A. M., Yadav, H., \& Arokiasamy, J. T. (2013). Adverse Health Effects and Unhealthy Behaviors among Medical Students Using Facebook. The Scientific World Journal, 2013.

Allison, T. R., Symmons, D. P. M., Brammah, T., Haynes, P., Rogers, A., Roxby, M., et al., (2002). Musculoskeletal pain is more generalised among people from ethnic minorities than among white people in Greater Manchester. Annals of the Rheumatic Diseases, 61(2), 151-156.

Błachnio, A., Przepiórka, A., \& Rudnicka, P. (2013). Psychological determinants of using Facebook: A research review. International Journal of Human-Computer Interaction, 29(11), 775-787.

Bosch, T. E. (2009). Using online social networking for teaching and learning: Facebook use at the University of Cape Town. Communicatio: South African Journal for Communication Theory and Research, 35(2), 185-200.

Buckman, R. (2005). Too much information? Colleges fear student postings on popular Facebook site could pose security risks. The Wall Street Journal, P. B1.

Denti, L., Nilsson, I., Barbopoulos, I., Holmberg, L., Thulin, M., Wendeblad, M., et al., (2012). Sweden's Largest Facebook study: A survey of 1,000 Swedish Facebook users. Gothenburg, Sweden: Gothenburg Research Institute.

Doku, D., Koivusilta, L., Raisamo, S., \& Rimpelä, A. (2013). Socio-economic differences in adolescents' breakfast eating, fruit and vegetable consumption and physical activity in Ghana. Public Health Nutrition, 16(05), 864-872.

Ellison, N. B., Steinfield, C., \& Lampe, C. (2007). The benefits of Facebook "friends:" Social capital and college students' use of online social network sites. Journal of Computer-Mediated Communication, 12(4), 1143-1168.

Ellison, N. B., Vitak, J., Gray, R., \& Lampe, C. (2014). Cultivating social resources on social network sites: Facebook relationship 
maintenance behaviours and their role in social capital processes. Journal of Computer-Mediated Communication, 19(4), 855870.

Faul, F., Erdfelder, E., Lang, A.-G., \& Buchner, A. (2007). G*Power 3: A flexible statistical power analysis program for the social, behavioural, and biomedical sciences. Behaviour Research Methods, 39, 175-191

Ghana Online. (2014). Top 10 African countries on Facebook. Accessed from http://www.myghanaonline.com/1.1692463 on 30 July 2014.

Golder, S. A., Wilkinson, D., \& Huberman, B. A. (2007, June). Rhythms of social interaction: Messaging within a massive online network. In C.Steinfield, B.Pentland, M.Ackerman, \& N.Contractor (Eds.), Communities and Technologies 2007: Proceedings of the Third International Conference on Communities and Technologies (pp. 41-66). London: Springer.

Hakala, P. T., Rimpelä, A. H., Saarni, L. A., \& Salminen, J. J. (2006). Frequent computer-related activities increase the risk of neckshoulder and low back pain in adolescents. The European Journal of Public Health, 16(5), 536-541.

Hew, K. F. (2011). Students' and teachers' use of Facebook. Computers in Human Behaviour, 27(2), 662-676.

Juul-Kristensen, B., Søgaard, K., Støyer, J., \& Jensen, C. (2004). Computer users' risk factors for developing shoulder, elbow and back symptoms. Scandinavian Journal of Work, Environment \& Health, 390-398.

Kalpidou, M., Costin, D., \& Morris, J. (2011). The relationship between Facebook and the well-being of undergraduate college students. Cyberpsychology, Behaviour, and Social Networking, 14(4), 183-189.

Kim, K., Ryu, E., Chon, M. Y., Yeun, E. J., Choi, S. Y., Seo, J. S., \& Nam, B. W. (2006). Internet addiction in Korean adolescents and its relation to depression and suicidal ideation: A questionnaire survey. International Journal of Nursing Studies, 43(2), $185-192$.

Kirschner, P. A., \& Karpinski, A. C. (2010). Facebook and academic performance. Computers in Human Behaviour, 26(6), $1237-1245$.

Kiss, J. (2014). Facebook's 10th birthday: From college dorm to 1.23 billion users. Retrieved from http://www.theguardian.com/ technology/2014/feb/04/facebook-10-years-mark-zuckerberg on 29 July 2014.

Kuss, D. J., \& Griffiths, M. D. (2011). Addiction to social networks on the internet: A literature review of empirical research. International Journal of Environmental and Public Health, 8, 3528-3552.

Lee, S. Y. (2014). How do people compare themselves with others on social network sites?: The case of Facebook. Computers in Human Behaviour, 32, 253-260.

Lewis, J. \& West, A. (2009). 'Friending': London-based undergraduates' experience of Facebook. New Media \& Society, 11(7), 12091229.

Nicklas, T. A., O'Niel, C., \& Meyers, L. (2004). The importance of breakfast consumption to nutrition of children, adolescents, and young adults. Nutrition Today 39, 30-39.

Peltzer, K., \& Pengpid, S. (2014). Nocturnal sleep problems among university students from 26 countries. Sleep and Breathing, (aheadof-print) 1-10, doi: 10.1007/s11325-014-1036-3

Peltzer, K., Pengpid, S., \& Apidechkul, T. (2014). Heavy internet use and its associations with health risk and health-promoting behaviours among Thai university students. International Journal of Adolescent Medicine and Health, 26(2), 187-194.

Pempek, T. A., Yermolayeva, Y. A., \& Calvert, S. L. (2009). College students' social networking experiences on Facebook. Journal of Applied Developmental Psychology, 30(3), 227-238.

Raacke, J., \& Bonds-Raacke, J. (2008). MySpace and Facebook: Applying the uses and gratifications theory to exploring friendnetworking sites. Cyberpsychology and Behaviour, 11(2), 169-174.

Rosen, L. D., Whaling, K., Rab, S., Carrier, L. M., \& Cheever, N. A. (2013). Is Facebook creating "iDisorders"? : The link between clinical symptoms of psychiatric disorders and technology use, attitudes and anxiety. Computers in Human Behaviour, 29(3), 12431254.

Sheldon, P. (2008). Student favourite: Facebook and motives for its use. Southwestern Mass Communication Journal, 23(2), 39-53.

Tobin, S. J., Vanman, E. J., Verreynne, M., \& Saeri, A. K. (2014). Threats to belonging on Facebook: lurking and ostracism. Social Influence, (ahead-of-print), 1-12. doi: 10.1080/15534510.2014.893924 